De Munari, A. Capão, D.P.S. ; Richards, B.S. ; Schäfer, A.I. (2009) Application of Solar-Powered Desalination in a Remote Town in South Australia, Desalination, $248,72-82$.

\section{Application of Solar-PoWered Desalination in a Remote TOWn In SOUTH} AUSTRALIA

A. De Munari ${ }^{1}$, D.P.S Capão ${ }^{2}$, B.S. Richards ${ }^{2}$, A.I. Schäfer ${ }^{1}$

${ }^{1}$ School of Engineering, University of Edinburgh, Edinburgh, EH9 3JL, United Kingdom, email: Andrea.Schaefer@ed.ac.uk

2 School of Engineering and Physical Sciences, Heriot-Watt University, Edinburgh, EH14 4AS, United Kingdom

Submitted to

Desalination 2009

Abstract: Coober Pedy is a remote town in South Australia with abundant solar radiation and scarce and low quality water, where a reverse osmosis plant has been operating since 1967. This paper evaluates the feasibility of powering the plant with solar or photovoltaic (PV) panels whilst avoiding energy storage in batteries. Pilot tests were performed in October 2005 with a small scale PV-powered hybrid ultrafiltration-reverse osmosis (UF/RO) membrane filtration system. The performance of the system in Coober Pedy is presented over different operating conditions and two available brackish feed waters. The system has been shown to tolerate well the power variation during clear sky days due to direct use of $\mathrm{PV}$ panels, producing $764 \mathrm{~L}$ of water per solar day with average specific energy consumption of $3.2 \mathrm{kWh} . \mathrm{m}^{-3}$ when treating the groundwater with conductivity of $7.4 \mathrm{mS} . \mathrm{cm}^{-1}$. It has been concluded that a reverse osmosis plant utilising UF pre-treatment and powered by PV panels without battery storage is a promising alternative for Coober Pedy to overcome currently high energy costs for the existing RO plant.

Keywords: Reverse osmosis; Solar energy; Photovoltaic; Brackish water; Ultrafiltration; Specific Energy Consumption

\section{Introduction}

Photovoltaic-powered membrane filtration (PV-membrane) systems have proven to perform satisfactorily in arid remote areas, where groundwater availability is low and of poor quality, rainfall is scarce but solar radiation is abundant [1-4]. This paper explores the application of such a system in Cooper Pedy, a town of 3500 inhabitants (plus about 1,000 tourists during winter) located in central Australia (latitude $29.00^{\circ}$ S, longitude 134.76 E). As shown in Figure 1, it can be classified as "very remote" [5]. The town receives a yearly average solar irradiation of $5.8 \mathrm{kWh} \cdot \mathrm{m}^{-2} \cdot \mathrm{d}^{-1}(1990-2008)$, while in the month of October the average daily solar irradiation is $6.78 \mathrm{kWh} \cdot \mathrm{m}^{-2} . \mathrm{d}^{-1}(1990-2008)$ [6] . There are on average 173.8 clear days per year (1965-1994) and 63.7 cloudy days per year (1965-1994) [6]

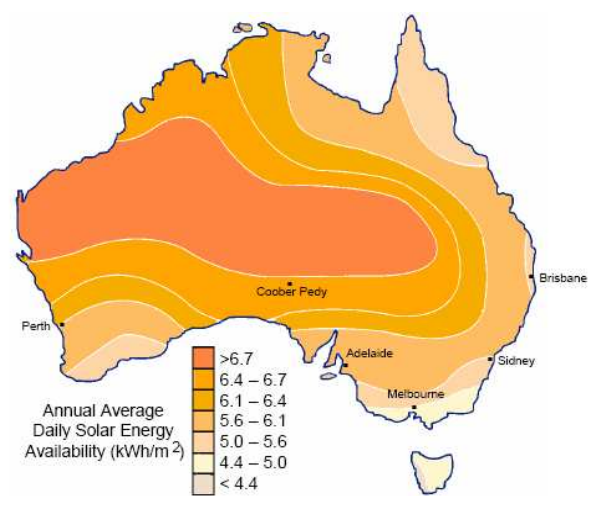

Figure 1 Map of Australia, showing the location of Coober Pedy and other cities as well as the average annual solar irradiance (reprinted with permission, ANZSES) [7]

The average monthly rainfall is $13 \mathrm{~mm}$ (1921-2008), with 30.4 rainy days per year (1921-2008) and the average rainfall for October is $15 \mathrm{~mm}(1921-2008)$ with 2.9 days of rain (1921-2008) [6]. The average maximum temperature throughout the year is $27.8^{\circ} \mathrm{C}(1965-1994)$ and in October the average maximum temperature is $28.90 \mathrm{C}$ (1965-1994) [6].

Groundwater at Coober Pedy has been mainly obtained from a sand aquifer, $60-80 \mathrm{~m}$ thick, which underlies the Bulldog Shale a weathered sedimentary and opal-bearing formation which reaches $110 \mathrm{~m}$ from the ground level [8]. The sand aquifer produces high salinity water with electrical conductivity (EC) of about $26 \mathrm{mS} \mathrm{cm}^{-1}$. In the north-west of the town, relatively low salinity water is present, with conductivity of about $7 \mathrm{mS}^{-\mathrm{cm}^{-1}}$. The leaching and shrinkage of the otherwise mpermeable Bulldog Shale during Palaeogene has created clusters of open spaces and saturated oints. Leakage of surface waters through fractures and cavities is believed to be the main cause of the lower salinity water occurrence in the underlying sand aquifer [8]

Throughout its history, Coober Pedy has always suffered water supply problems, both of quantity and quality. Before 1921, rainfall was collected in natural holes, such as the Five Miles Water Hole. In 1916 the government drilled four wells, but the water was too salty for potable use. In 1922, an underground cement water tank of $2 \mathrm{ML}$ capacity was built for rainwater collection, but it was only reverse oly filled by 1926 [9]. At that time the water was mainly carted from miles away. In 1967 sizable community in Australia to be served by a dealination plant [8]. The SD plant produced $130{\mathrm{~L} . \mathrm{d}^{-1}}^{-1}$ of good quality water that was mixed with water from the less efficient RO plant. The total water produced was not enough to meet the demand and $110 \mathrm{~L}$ per person per week were allowed. The solar still reported severat problems, 
clogging of black plastic-lined trays by iron oxides, glass panel damages by crows trying to drink water and leaks due to clay ground subsidence during rain [10].

Figure 2 shows the current RO plant of $850 \mathrm{~m}^{3} \cdot \mathrm{d}^{-1}$ capacity that was commissioned in 1985, while Figure 3 shows the second back-up RO plant that was built in 2001 as a capacity increase of 600 $\mathrm{m}^{3} . \mathrm{d}^{-1}$. The RO plants are located close to the town centre and they pump low salinity water from a bore located $25 \mathrm{~km}$ north of town. The $2 \mathrm{ML}$ water tank built in 1921 was re-lined and covered [11] and another underground 2.2 ML tank was built to serve as water storage tanks [12].

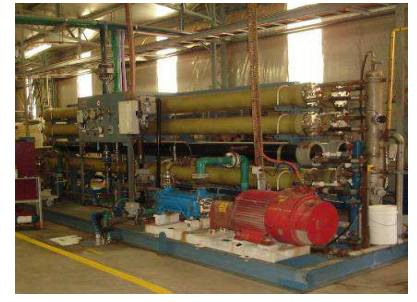

Figure 2 RO unit constructed in 1985

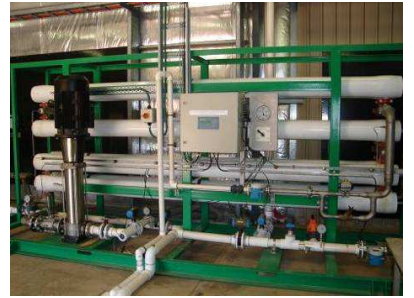

Figure 3 Backup RO unit constructed in 2001
The plants are managed by the Water Supply Department of Districted Council (manager plus 4 staff). The RO plants are equipped with FILMTEC ${ }^{\mathrm{TM}}$ BW30 membranes [13] and with $5 \mu \mathrm{m}$ pre-treatmen filters. The plants achieve good water quality but they suffer from filter clogging, as shown in Figure 4 The permeate is pumped to the town water supply network, while the concentrate is disposed in the creek near by the plants as shown in Figure 5 . With a recovery of $75 \%$, about $1080 \mathrm{~m}^{3}$ of concentrate
are potentially discharged into the environment every day.

Coober Pedy is not connected to the Australian electricity grid and currently obtains all its power from diesel generators. Both the RO plants are currently powered by diesel and gas and they consumes $40420 \mathrm{kWh}$ per month, excluding the power for pumping the water to and from the plants [12]. The operational cost for the diesel consumed for the RO plants is about $A \$ 14,000$ per month [12]. The treated water is sold at $\mathrm{A} \$ 3.10-4.80$ per $\mathrm{m}^{3}$, with higher prices being paid for increased consumption. The treated water is also available - mainly for tourists - from an on-street coin operated dispensers (shown in Figure 6) at $\mathrm{A} \$ 0.20$ per $30 \mathrm{~L}(\mathrm{~A} \$ 6.67 / \mathrm{m} 3)$.

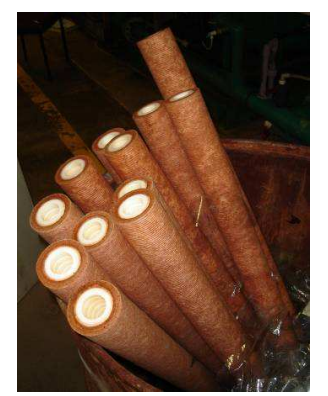

Figure 4 Filters for existing RO plants clogged by feed water iron content

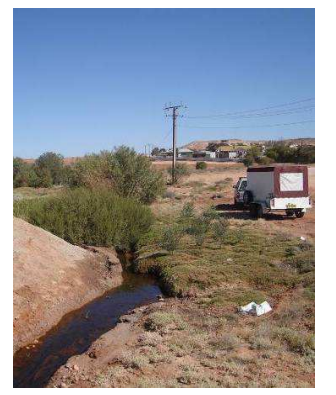

Figure 5 'Concentrate Creek' for RO plants

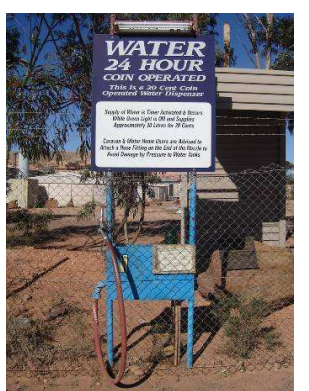

Figure 6 Coin operated water offering $30 \mathrm{~L}$ for $\mathrm{A} \$ 0.20$ dispenser in Coober Pedy
Given the geographical characteristics of Coober Pedy, the high solar radiation it receives, the scarcity of rainfall, its water needs and the existence of two RO plants, the use of photovoltaic panels, converting solar energy to electricity, to power RO process can be a sustainable alternative to traditional energy sources.

The aim of this paper is the evaluation of the feasibility of a photovoltaic-powered RO plant for Coober Pedy. For this purpose, pilot tests with a small scale reverse osmosis solar desalination (PVmembrane) system have been performed in Coober Pedy (Figure 7). The performance of the system will be evaluated as specific energy consumption (SEC), water productivity and salt retention when the unit will be operating under fluctuating energy conditions

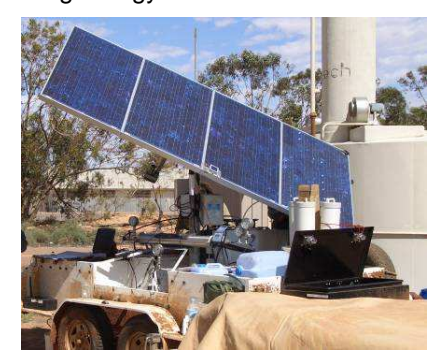

Figure $7 \mathrm{PV}$ powered hybrid UF/RO unit used in this trial.

\section{Materials and Methods}

The system uses PV modules to power a two-stage membrane process. The first membrane stage consists of six Zenon ZW10 ultrafiltration (UF) membranes connected in parallel and immersed in a $300 \mathrm{~L}$ stainless steel tank. The second stage consists of a NF/RO membrane module chosen according to the water to be treated. The system is powered by two $24 \mathrm{~V}_{\mathrm{DC}}$ (nominal) PV modules (BP solar, BP3150S), rated at 150W peak (under standard test conditions of $1000 \mathrm{~W} \cdot \mathrm{m}^{-2}$ ). The system was
described in detail by Schäfer et al. [14] who evaluated the optimal operating window of the PVmembrane system at a bore in the Northern Territory, Australia [15].

The progressive cavity (PC) pump sucks feedwater through the UF membranes at negative suction pressure of about -0.5 bar, pressurising the UF permeate through the NF/RO module (maximum 12 a sor). The system is not currently designed to power he bore pump needed to collect groundwater, as W solar powered water pumping system can be usority of the ren, being a well established and reliable technology. includes batteries to allow operation during night and cloudy days and to avoid energy fluctuations [1$4,16,17]$, the proposed system has no batteries and relies on water storage. Batteries are not ideal as they decrease the system efficiency, increase the system maintenance and the risk of strong chemical spillage. As a consequence, the system operates at variable power, hence variable flow and pressure [15].

Depending on membrane choice, water quality and operating conditions, the system provides about $1000 \mathrm{~L}$ of desalinated drinking water per solar day, but it can be scaled up because the PV modules and the membranes are modular technologies. The system was tested during a six week period in six different locations, for a total of 53 field trials [5]. Field trials at Pine Hill Station ( $140 \mathrm{~km}$ north west of Alice Springs) $[14,15]$ demonstrated a good and stable short term performance of the system. The system achieved the Australian Drinking Water Guidelines (ADWG) [18] for brackish water with conductivity of $8.29 \mathrm{mS}^{-\mathrm{cm}^{-1}}$ when RO membranes were used and equal or lower SEC than other systems that are operated with energy recovery [14].

The above described unit was tested at Coober Pedy in late October 2005. The aim of the pilot tests was to evaluate the feasibility of the PV-membrane system without batteries, investigating the effects 

of energy fluctuations on the RO membranes. In particular, the tested system was felt to be well suited
for Coober Pedy as the UF membranes pre-treat the water to be fed to the RO membranes, avoiding for Coober Pedy as the UF membranes pre-treat the water to be fed to the RO membranes, avoiding fouling. The UF membranes remove suspended solids, colloids, particulates, bacteria, viruses and some organic matters, preventing their deposition on the RO membranes [19]. Coober Pedy RO plants make extensively use of antiscalants and cleaning products to avoid membrane fouling/scaling. [13], the same RO membranes used in the existing RO plants.

During the field experiments the power requirements were monitored manually from the electronic interface of the pump. The feed, permeate and concentrate flows were determined manually. Electrica conductivity and temperature for feed, permeate and concentrate were measured with conductivity probes and thermometers. Manual measurements and sampling of process streams were performed every 0.5-1 hour. Pressure was measured at $5 \mathrm{~s}$ intervals with transducers located upstream and downstream of the pump and on the concentrate stream after the RO membranes. Solar irradiation was measured with a temperature-compensated sensor mounted in the same plane as the PV modules. Pressure and solar irradiation data were supplied to a data logger (DataTaker DT500) and downloaded to a laptop. Membrane specific parameters, such as transmembrane pressure TMP, recovery $\mathrm{Y}$, retention R, flux J, SEC and the concentration of total dissolved solids TDS were consecutively calculated using the relationships described by Schäfer et al. [14] and Richards et al. [15].

In order to investigate the performance of the system, three pilot tests were performed at Coober Pedy. The first and second tests were run with the low salinity water (conductivity of feed flow at the experiment start of $7.41 \mathrm{mS} . \mathrm{cm}^{-1}$ and $7.57 \mathrm{mS} . \mathrm{cm}^{-1}$ respectively) which is fed to the existing full scale RO plants. The first pilot test was performed on 26 October 2005 with the system in a batch mode, i.e. the permeate and concentrate were continuously recycled back to the feed tank. Before sunrise the feed tank was filled and a back-pressure valve was manually set to provide pressure of 7 bar at feed flow of $300 \mathrm{~L} . \mathrm{h}^{-1}$. The system was then left to run powered by solar energy without any further manipulation of the valves until sunset, when the system shut down automatically. The second pilot test was performed on 27 October 2005 in a continuous mode. In this mode, the feed tank was continuously filled directly from the bore and the permeate and concentrate were discarded. The backpressure valve was set for 7 bar at feed flow of 300 L.h $^{-1}$ before starting and left to run till sunrise without intervention. The batch mode experiment allowed testing the system with constant feed wate characteristics, while the continuous mode test was aimed to reproduce a more realistic performance of the system over time. The third pilot test was performed on 31 October 2005 in a batch mode as the first test but with the high salinity water (EC of about $26 \mathrm{mS} . \mathrm{cm}^{-1}$ ) which occurs in the majority of the Coober Pedy area. A continuous experiment of this water was performed on 29 October 2005 but abandoned due to poor weather conditions.

\section{Results and Discussion}

Table 1 shows the daily average performance of the system for each test. The three days in which the field experiments were performed presented clear sky conditions and average daily solar irradiation of $7.4 \mathrm{kWh} \cdot \mathrm{m}^{-2} \mathrm{~d}^{-1}$, comparable to the average solar radiation values for the month of November ( 7.61 $\mathrm{kWh} \cdot \mathrm{m}^{-2} \mathrm{~d}^{-1}$ ). It should be noted that the solar panels in the PV-membrane system are able to collect $30 \%$ more solar radiation due to the single-axis (east-west) tracker [15]. Weather conditions influence the membrane performance, therefore similar conditions for the three tests facilitate the comparison of the results.
Table 1 Daily average results for pilot tests at Coober Pedy

\begin{tabular}{|c|c|c|c|c|c|c|}
\hline Date & $\begin{array}{l}\text { Experiment } \\
\text { Mode }\end{array}$ & Weather & $\begin{array}{c}\text { Solar } \\
\text { Irradiation } \\
\left(\mathrm{kWh} \cdot \mathrm{m}^{-2} \cdot \mathrm{d}^{-1}\right)\end{array}$ & $\begin{array}{l}\text { Power } \\
\text { (W) }\end{array}$ & $\begin{array}{l}\text { TMP } \\
\text { (bar) }\end{array}$ & $\begin{array}{c}\text { Flux } \\
\left(\text { L. } \mathrm{m}^{-2} \cdot \mathrm{h}^{-1}\right)\end{array}$ \\
\hline $26 / 10 / 05$ & batch & clear sky & 10.2 & 209 & 10.2 & 9.1 \\
\hline $27 / 10 / 05$ & continuous & clear sky & 10.3 & 210 & 10.4 & 9.1 \\
\hline $30 / 10 / 05$ & batch & clear sky & 10.9 & 210 & 10.0 & 1.3 \\
\hline $\begin{array}{c}\text { Recovery } \\
\text { Y (\%) }\end{array}$ & $\begin{array}{c}\text { Retention } \\
\mathrm{R}(\%)\end{array}$ & $\begin{array}{l}\text { EC Feed } \\
\left(\mathrm{mS}^{\left.-\mathrm{cm}^{-1}\right)}\right.\end{array}$ & $\begin{array}{c}\text { EC permeate } \\
\left(\mathrm{mS}^{\left.-\mathrm{cm}^{-1}\right)}\right.\end{array}$ & $\begin{array}{c}\text { EC concentrate } \\
\left(\mathrm{mS}^{\left.-1 \mathrm{~cm}^{-1}\right)}\right.\end{array}$ & $\begin{array}{c}\text { SEC } \\
\left(k W h \cdot m^{-3}\right)\end{array}$ & $\begin{array}{l}\text { Total permeate } \\
\text { volume }\left(L . d^{-1}\right)\end{array}$ \\
\hline 17.5 & 96.3 & 7.47 & 0.28 & 8.84 & 3.2 & 764 \\
\hline 17.5 & 95.9 & 7.36 & 0.30 & 8.68 & 3.2 & 764 \\
\hline 2.3 & 75.4 & 25.83 & 6.35 & 26.24 & 24.5 & 111 \\
\hline
\end{tabular}

The average power measured at the pump interface for the three tests reflects the solar irradiation values. The power of the PC pump determines the pressure at its input stream (UF suction pressure) and at its output stream (RO feed pressure) and the feed flow. The power of the pump determines therefore the TMP, i.e. the difference between the average of feed and concentrate pressure and permeate pressure [15]. While the TMP of the three tests is of the same order of magnitude, the flux (permeate flow/membrane area) during the third test is considerably lower. This is due to the high salinity content of the feed water that presents conductivity values more than three times higher than the low salinity water used for the first two tests. In RO membranes the driving force for the transport of water is given by the pressure gradient across the membrane (TMP). However, the rejection of dissolved salts results in a pressure gradient that acts against the flow, called osmotic pressure $(\Delta \pi)$.

For the high salinity water the pressure exerted by the pump is not sufficient to create a significant permeate flow through the membrane, as the osmotic pressure to overcome is too high. The system tested is limited by the pump to a certain pressure (12 bar) and cannot successfully treat such salin water, unfortunately. Therefore, the average recovery (permeate flow/feed flow) and the tota permeate volume produced are considerably lower than in the low salinity tests and the SEC (power/permeate flow) are very high. Retention (percentage of salts retained by the membrane) is thickness and it is responsible for the concentration polarisation effects. Concentration polarisation hickness and it is responsible for the concentration polansation eftects. Concentration polarisation the high salinity water and the average conductivity in the permeate is greater than $0.78 \mathrm{mS} \mathrm{cm}^{-1}$, the

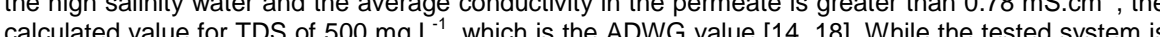
not able not able to meet water quality standards when fed by two tests.

It can be observed that the water quality obtained from the first two tests is much higher than the ADWG value; additionally the World Health Organization established a maximum TDS values of 1000 mg.L [21] and taste preference of locals in Australian remote communities is towards drinking water saltier than $500 \mathrm{mg.L} \mathrm{L}^{-1}[14]$. This means that membranes with lower retention, potentially higher recovery and hence higher flux can be used which will result in a lower SEC. Concentrate obtained from low salinity water may be used for other household applications or stock irrigation [5] while currently it is discarded untreated to the environment, as shown in Figure 5. 
For both batch and continuous tests with low salinity water, permeate production is $764 \mathrm{~L}$ per solar day and average SEC is $3.2 \mathrm{kWh} . \mathrm{m}^{-3}$. Schäfer et al. [14] compared SEC values with results published for brackish PV-membranes systems, and SEC depends on the feed water salinity and on the system size. Figures 8-10 a-h show the varialion of the system performance when operating with variable energy where: (a) is power; (b) feed flow; (c) ThP; (d) UF (suction) pressure; (e) flux; (f) EC of feed with the solar irradiance.
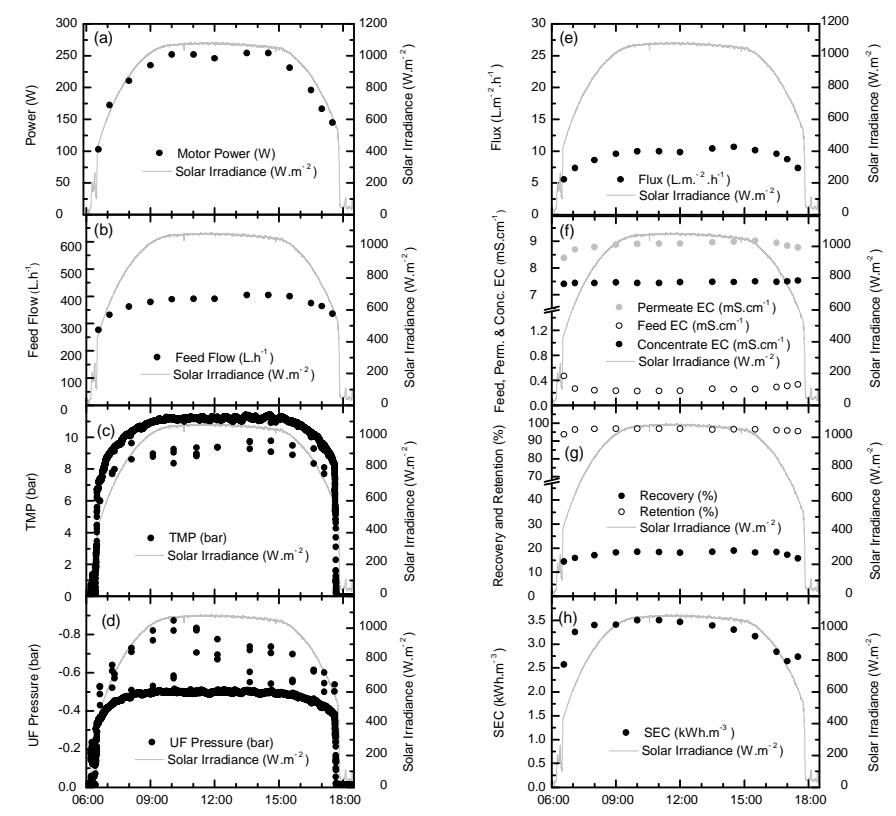

Figure 8 Performance of the unit tested on 26 October 2005 at Coober Pedy - Batch mode low salinity water

During clear days, as was the case during those experiments, the fluctuations of irradiance are minimum and the amount of energy received by solar panels is maximum [22]. Solar radiation is at its maximum from about $9 \mathrm{am}$ to $3 \mathrm{pm}$ and increases and decreases sharply before 9 am and after $3 \mathrm{pm}$, respectively. The system starts and ends operation when the available power drops below the minimum requirement. The system operates for almost 12 hours in this location and month with the maximum power of $254 \mathrm{~W}$ during the midday plateau.

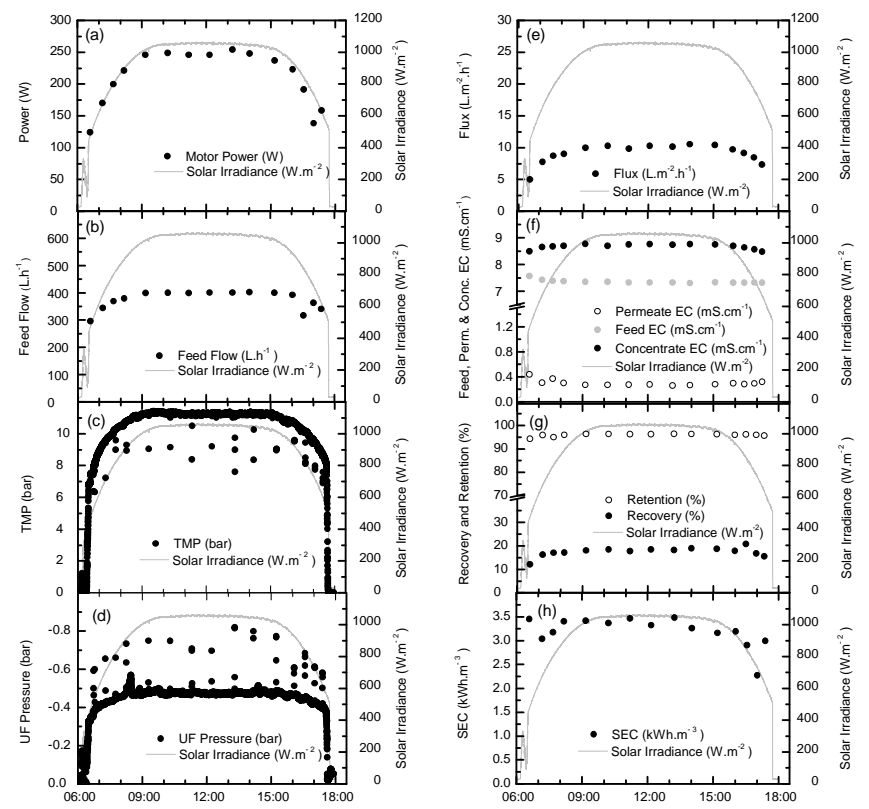

Figure 9 Performance of the unit tested on 27 October 2005 at Coober Pedy - Continuous mode low salinity water

Irradiance translates into power available to the system (Fig 8-10a) depending on the area of PV panels $\left(1.6 \mathrm{~m}^{*} 0.8 \mathrm{~m}\right.$ per panel) and the efficiency (about $12 \%$, decreasing at high temperatures). In turn, the power fluctuations of the pump affect the flow and the pressure supplied by the pump. In particular, the power fluctuations directly affect the feed llow to the RO membrane (Fig 8-10b), TMP (Fig 8-10C) and the negative UF pressure (Fig 8-10d) which in consequence affect hydrodynamics and diffusion. Abrupt variation of operating parameters such as flow and pressure may in fact damage the maximu maximum pressur seconds [13].

As shown in Figures 8-10b the feed flow has low variations through the day for all the experiments, with highest variation during the third experiment of $0.2 \mathrm{~m}^{3} \cdot \mathrm{h}^{-1}$ in 1 hour, which does not affect the membrane integrity. The UF pressure and the TMP shown in $8-10 \mathrm{c}, \mathrm{d}$ are more affected by the powe fluctuations. However, the maximum TMP variation experienced was of 35 bar.min (Figure 9c) and again this is within the design specifications. The "scattered" points in Figures 8-10c,d represent about $0.3 \%$ of all data points in the curve and are thought to be due to sensor problems during the tests. The flux, hence the permeate flow, follows the evolution of TMP, as shown in Figures 8-10e. The values are lower than the design flux of those membranes $\left(52.7 \mathrm{~L} . \mathrm{m}^{-1} \cdot \mathrm{h}^{-1}\right)$ which means that a higher than necessary membrane area is required; however, fouling will be reduced which is a significan benefit in remote locations. 

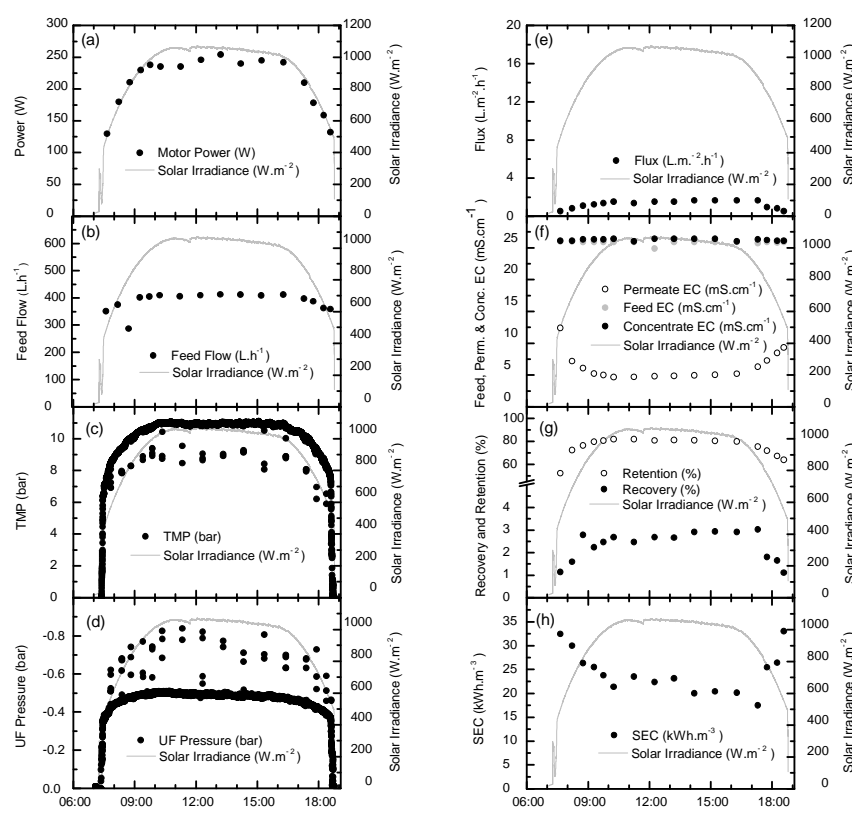

Figure 10 Performance of the unit tested on 30 October 2005 at Coober Pedy - Batch mode high salinity water

Figures 8-10f present the daily variations of the feed, permeate and concentrate EC. The feed EC is generally constant during the day, the concentrate EC depends on the permeate EC. The permeate $E C$ is higher at the beginning and at the end of the day when less solar radiation and hence power is available to produce flow and pressure. However, for the first two experiments this variation is minima and the permeate conduclivity is always lower than $0.78 \mathrm{mS}$.cm. This varialion is more marked for high salnily water, whe con and the required permeate quality is ne sublantial due to the insuficient

Recovery and retention, shown in Figures 8-10g, have low variations in the first two experiments but high variation in the third experiment. This is expected as the recovery and retention are derived from previous parameters. The system is designed for a low recovery of about $10 \%$ with the idea to change the feedwater EC substantially and in consequence allow further usage of this physically disinfected water for non-drinking applications. SEC, shown in Figures $8-10 \mathrm{~h}$, shows values of $3-3.5 \mathrm{kWh} . \mathrm{m}^{-3}$ for the low salinity experiments. This is somewhat higher than values of about $2 \mathrm{kWh} \cdot \mathrm{m}^{-3}$ for a slightly more saline water. While more work is required on this issue, a higher SEC is most likely related to higher fouling of the membranes.

In summary, for the low salinity water tested, power variation during clear sky days due to direct use of PV panels without batteries does not affect the permeate conductivity, hence the water quality, and has minimal influence on the permeate production. The PV-membrane system is able to tolerate energy in exceed the membrane manufacturer recommended values. Batch and continuous tests present similar results and trends, showing that the system performs satisfactorily under variations of feed water characteristics for the low salinity water tested. However, longer experiments need to be performed to test the efficiency of the system with time and its performance under different fluctuating weather conditions.

In order to power the existing RO plants with PV panels, $1900 \mathrm{~m}^{2}$ of PV modules BP solar (BP3150S) would be required. If higher efficiency panels, such as SunPower SPR-210 [23] were to be mounted on single-axis solar tracker, the area required would decrease to $1192 \mathrm{~m}^{2}$. The installation costs for the high efficiency panels would be $\mathrm{A} \$ 2,115,000$. Considering yearly maintenance costs of the PV panels equal to $0.5 \%$ of the capital cost, inverter maintenance costs (occurring every 10 years) equal to $12 \%$ of the capital cost and PV panels lifetime of 20 years, the Net Present Value (NPV) for the PV panels installation and maintenance at $8 \%$ discount rate would be $A \$ 2,076,500$. As said before, the existing RO plants have operational costs of $A \$ 14,000$ per month due to use of diesel generators [12] If diesel prices in Australia continue to increase at the same pace as in the 2004-2007 period (average 9.5\% per year [24]) the NPV of the fuel costs for 20 years (8\% discount rate) would be $A \$ 3,558,000$. The installation of PV panels would have a pay back of less than 13 years and it would save up to A $\$ 1,481,500$. Furthermore, if financial support is obtained by the Australian Government's Renewable Remote Power Generation Program (RRPGP) [25], which provides rebates up to $50 \%$ of the capital cost of renewable generation, the NPV of the PV installation and maintenance would be $A \$ 1,143,650$ resulting in $A \$ 2,414,350$ saved and panels pay back of less than 8 years.

\section{Conclusions}

A small scale reverse osmosis desalination system powered by solar panels without any battery storage has been tested in Coober Pedy, South Australia. Reverse osmosis is a relatively energyintensive technology and in remote areas with abundant solar radiation as Coober Pedy, photovoltaic panels can be a sustainable alternative to traditional energy sources. The results of pilot tests performed over three days in October 2005 have been presented in this paper. The system achieved very good water quality standards and SEC of $3.2 \mathrm{kWh} . \mathrm{m}^{-3}$ when treating 'low salinity water' (EC 7.4 $\mathrm{mS} . \mathrm{cm}^{-}$) Which is currently used for the town water supply following RO, but it did not perform well with 'high salinity water' (EC $25.6 \mathrm{mS} . \mathrm{cm}^{-1}$ ) due to this exceeding the design EC of the system. For the lower salinity water, the system has been shown to tolerate well power increase and decrease during clear sky days due to direct use of PV panels, as the quality and quantity of the produced water has been minimally affected. The tested RO pilot plant powered by PV panels without battery storage is a promising solution for low salinity water treatment in Coober Pedy. Powering the existing RO plants with PV panels has been shown to be a viable economic solution.

\section{Acknowledgments}

In addition to the contributions acknowledged in our previous work [14], the authors would like to extend thanks, firstly, to Les Hoad, manager of the RO plants at Coober Pedy for the valuable information provided, secondly, to the Drinking Water Quality Regulator for Scotland and The Schoo of Engineering of the Universty of Edinburgh for providing PhD studentship for De Munari and, thirdly, to the School of Engineering and Physical Sciences (HWU) and the Nielson Fund (Mechanical Engineering) for a PhD studentship for Capão.

\section{References}

[1] Alawaji S, Smiai MS, Rafique S, Stafford B. PV-powered water pumping and desalination plant for remote areas in Saudi Arabia. Applied Energy 1995; 52: 283-289.

[2] Al Suleimani Z, Nair VR. Desalination by solar-powered reverse osmosis in a remote area of

the Sultanate of Oman. Applied Energy 2000; 65: 367-380.

[3] Harrison DG, Ho GE, Mathew K. Desalination using renewable energy in Australia. Renewable Energy 1996; 8: 509-513.

[4] Herold D, Neskakis A. A small PV-driven reverse osmosis desalination plant on the island of

Gran Canaria. Desalination 2001; 137: 285-292.

[5] Werner M, Schafer Al. Social aspects of a solar-powered desalination unit for remote Australian communities. Desalination 2007; 203: 375-393. 
De Munari, A. Capão, D.P.S. ; Richards, B.S. ; Schäfer, A.I. (2009) Application of Solar-Powered Desalination in a Remote Town in South Australia, Desalination, $248,72-82$.

doi: 10.1016/j.desal.2008.05.040

[6] Bureau of Meteorology. Climate Statistics for Australian Locations,

http://www.bom.gov.au/climate/averages/tables/cw 016007 All.shtml, accessed March 2008.

7] Lee T, Oppenheim D, Williamson T. Australian Solar Data Radiation Handbook (ASDRH), Energy Resource Development Council, Australia, 1995. Copyright now held by Australian and New Zealand Solar Energy Society (ANZSES).

[8] Taylor G, Eggleton RA. Regolith Geology and Geomorphology John Wiley and Sons, 2001.

[9] Britt S. Historic Water Solutions. Coober Pedy Regional Times, Issue 31 May - 13 June 2007.

10] Britt S. Historical Solutions to Coober Pedy's Most Urgent Need - Water. Coober Pedy

Regional Times, Issue 14 June - 27 June 2007.

[11] Britt S. Reverse Osmosis Desalination Plant - Tour with Les Hoad. Coober Pedy Regiona

Times, Issue 12 July - 25 July 2007.

12] Personal Communication with Les Hoad, 26 October 2005.

13] Dow Water Solution Membrane FILMTEC BW30-4040 Datasheet.

http://www.dow.com/liquidseps/prod/bw30 4040.htm, accessed on March 2008.

[14] Schäfer Al, Broeckmann A, Richards BS. Renewable Energy Powered Membrane Technology. 1 Development and Characterization of a Photovoltaic Hybrid membrane System. Environ. Sci.

[15] Richards BS, Capão DPS, Schäfer Al. Renewable Energy Powered Membrane Technology. 2 The effect of energy fluctuations on performance of a photovoltaic hybrid membrane system. Environ. Sci. Technol 2008; 42: 4563-4569.

[16] Petersen G, Fries S, Mohn J, Muller A. Wind and solar powered reverse osmosis desalination units - design, start up, operating experience. Desalination 1981; 39: 125-135.

[17] Weiner D, Fisher D, Moses EJ, Katz B, Meron G. Operation experience of a solar- and wind-

powered desalination demonstration plant. Desalination 2001; 137: 7-13.

[18] National Health and Medical Research Council. Australian Drinking Water Guidelines; Nationa Health and Medical Research Council, National Water Quality Management Strategy, Canberra, Australia, 2004.

[19] Cote P, Cadera J, Coburn J, Munro A. A new immersed membrane for pretreatment to reverse osmosis. Desalination 2001; 139: 229-236.

[20] Mulder M. Basic Principles of Membrane Technology. Dordrecht: Kluwer Academic Publishers, 2000

[21] World Health Organization (WHO). Guidelines for drinking-water quality, 2006.

22] Kawasaki N, Oozeki T, Otani K, Kurokawa K. An evaluation method of the fluctuation

characteristics of photovoltaic systems by using frequency analysis. Solar Energy Materials and Solar Cells 2006; 90: 3356-3363.

[23] SunPower Solar Panel SPR-210 Datasheet.

http://www.sunpowercorp.com.au/theme/sunpower/downloads/sp 210bk res en a4 p r0 ds.pdf, accessed on April 2008.

[24] Daily data on the average Terminal Gate Prices (Wholesale) for diesel for Adelaide 2004-2007. http://www.aip.com.au/pricing/tgp.htm, accessed on April 2008.

25] Australian Government's Renewable Remote Power Generation Program (RRPGP).

http://www.environment.gov.au/settlements/renewable/rrpgp/index.html\#major, accessed on Apri 